\title{
Pomegranate Peels Activated Carbon by Phosphoric Acid Activation: Preparation, Characterization and Evaluation of Adsorptive Properties
}

\author{
Souad Najar-Souissi, Wafa Saadi, Manel Zarroug and Abdelmottaleb Ouederni \\ Research Laboratory of Engineering Processes and Industrial Systems, \\ National Engineering School of Gabes, University of Gabes, St. Omar Ibn El-Khattab, \\ 6029 Gabes, Tunisia Souad.najar@enig.rnu.tn
}

\begin{abstract}
Pomegranate peels, a by-product of agriculture are transformed by chemical activation with phosphoric acid into activated carbon. The raw material is impregnated with a $\mathrm{H}_{3} \mathrm{PO}_{4}$ solution with different ratios and impregnation time. The impregnated precursor is activated at different temperatures and times. The specific surface area was determined for all samples. The optimum activated carbon obtained is mainly microporous. Its BET specific surface area is approximately $1600 \mathrm{~m}^{2} / \mathrm{g}$ and its pore volume is $1.118 \mathrm{~cm}^{3} / \mathrm{g}$ which about $90 \%$ is micropores. The average pore diameter is about $3 \mathrm{~nm}$. Boehm titration and IR spectroscopy show the presence of oxygen functions on the surface, essentially acidic. The adsorbent capacity of this carbon is tested using three model molecules phenol, nitrophenol and methylene blue. The adsorption isotherms of the three molecules follow well the Langmuir model. The maximum adsorption capacities obtained are 119, 286 and $588 \mathrm{mg} / \mathrm{g}$ for phenol, nitrophenol and methylene blue, respectively. The optimum carbon, thus, obtained has interesting characteristics comparable to others carbons derived from lignocellulosics materials and commercial activated carbons. It can serve as a very good adsorbent in the aqueous phase, especially, for the removal of cationic dyes.
\end{abstract}

Key words: Pomegranate peels, activated carbon, process optimization, phosphoric acid, characterization, adsorption

\section{INTRODUCTION}

Domestic, agricultural and industrial discharges are damaging to our environment in all its components, water, air and soil. These effluents contain toxic substances with variable contents of which a large part is not biodegradable. Finding solutions to pollution problems is becoming a priority for governments. The valorization of biomass wastes in particular those resulting from agriculture by transformation into activated carbon can contribute to the resolution of these environmental problems in particular in the fields of treatment of gaseous and liquid discharges.

Activated Carbon (AC) is a very porous carbon material. It exists in powder, granular or fiber form (Marsh and Reinoso, 2006). It can be used as adsorbent (Moreno-Castilla, 2004), catalyst or catalyst support (Lam and Luong, 2014). Its uses as adsorbent covers pollutants of organic or mineral origin. Its performance in adsorption depends on its textural characteristics such as surface area and porosity and its chemical functions on its surface (Prahas et al., 2008).
The nature of the raw material and the process followed for its manufacture are largely responsible for these characteristics (Girgis and El-Hendawy, 2002). Two processes are adopted to prepare $\mathrm{AC}$; the thermal (or physical) process and the chemical process (Caturla et al. 1991) the thermal process consists of pyrolysis of the raw material followed by activation in the presence of an oxidizing agent such as water vapor (Ouederni et al., 2006) or $\mathrm{CO}_{2}$ (Nabais et al., 2013).

Chemical activation consists of the impregnation of the raw material with a chemical agent such as $\mathrm{NaOH}$ (Tongpoothorn et al., 2011), $\mathrm{KOH}$ (Saadi et al., 2016), $\mathrm{ZnCl}_{2}$ (Miao et al., 2013), $\mathrm{K}_{2} \mathrm{CO}_{3}$ (Hayash et al., 2002) and $\mathrm{H}_{3} \mathrm{PO}_{4}$ (Lim et al., 2010) followed by activation of the impregnated material in inert atmosphere. The combination of two methods can also be applied (Budinova et al., 2006).

Recently, chemical activation is widely used because it has several advantages. On the one hand, it is carried out in a single step and at a reduced time and a lower temperature resulting in energy saving. On the other hand, the $\mathrm{AC}$ obtained by this type of process has a high

Corresponding Author: Souad Najar-Souissi, Research Laboratory of Engineering Processes and Industrial Systems, National Engineering School of Gabes, University of Gabes, St Omar Ibn El-Khattab, 6029 Gabes, Tunisia $+21698544105 ;+21675392190$ 
specific surface area and a higher yield (Prahas et al., 2008). Among the activating agents which appears effective for the impregnation of lignocellulosic precursors, there is the orthophosphoric acid $\mathrm{H}_{3} \mathrm{PO}_{4}$. This is because it is not polluting and easy to recover when washing the $\mathrm{AC}$. The $\mathrm{AC}$ resulting from this process has applications in the food industry, pharmaceutical and the fine chemistry (Reddy et al., 2012).

Different agricultural by-products have been tested to prepare activated carbon. Among these materials that are effecttive, we quote: coconut shells (Hayash et al., 2002), almond shells (Nabais et al., 2011), olive stones (Ouederni et al., 2006), date stones (Ahmed, 2011), apricot stones (Aygun et al., 2003), bagasse (Kalderis et al., 2008), rice husk (Cheenmatchaya and Kungwankunakorn 2014), corn cobs (El-Sayed et al., 2014) and cotton stalks (Girgis and Ishak, 1999).

In our recently published research Saadi et al. (2016), we used pomegranate peels to prepare chemically activated carbon using $\mathrm{KOH}$ as an activating agent. The resulting $\mathrm{AC}$ had very interesting textural and adsorption characteristics. This encouraging result and the reduced number of publications (Senthilkumar et al., 2017; Serafin et al., 2017) interested in the production of the AC from this precursor and still the availability of this waste of agriculture in our region (Saad et al., 2012) pushed us to test this precursor for the preparation of $\mathrm{AC}$ by chemical activation using $\mathrm{H}_{3} \mathrm{PO}_{4}$ acid. We study the effect of the operating parameters on the specific surface area of the final product in order to optimize these parameters. The optimum product which having the high specific surface area is characterized physically and chemically and applied in the adsorption in aqueous solution of hazardous molecules such as phenol, 2-nitrophenol and methylene blue.

\section{MATERIALS AND METHODS}

Pomegranate Peels (PP) used for preparation of activated carbon were obtained from our region (Gabes) in the South of Tunisia. They were washed abundantly with distilled water then dried at temperature $105^{\circ} \mathrm{C}$ during 1 night. After that, they are crushed in to a number of particles with diameter of $1.5-5 \mathrm{~mm}$.

The contents of dried pomegranate peels were as follows: moisture content, 9.78\%, Ash, 2.75\%, Carbon $43.13 \%$, Hydrogen, $7.17 \%$, Nitrogen, $0.46 \%$, Sulfur, $0.89 \%$ and Oxygen (by difference), $48.35 \%$.

Preparation of activated carbon: At the beginning, the $\mathrm{PP} / \mathrm{H}_{3} \mathrm{PO}_{4}$ solution (50\% in weight) were mixed at impregnation ratio (weight of activating agent solution/weight of raw material) varying from 2-5. The mixture is stirred at boiling for $3 \mathrm{~h}$ (about $112^{\circ} \mathrm{C}$ ). After filtration, the solid is dried in the ambient for $24 \mathrm{~h}$ and then carbonized at the temperature of $400^{\circ} \mathrm{C}$ for $3 \mathrm{~h}$. The impregnation ratio resulting in the $\mathrm{AC}$ with the highest specific surface area is fixed for the following experiments. Then, the impregnation time is varied from $2-4 \mathrm{~h}$ while maintaining the other parameters constant (impregnation ratio previously optimized, carbonization temperature $400^{\circ} \mathrm{C}$, carbonization time $3 \mathrm{~h}$ ). The same procedure is followed to optimize the carbonization parameters. The temperature is varied in the range $300-500^{\circ} \mathrm{C}$ and the time between 2 and $4 \mathrm{~h}$. To prepare activated carbon, a weight of $25 \mathrm{~g}$ of acid-impregnated PP was carried out in a stainless steel tubular reactor (diameter of $21 \mathrm{~mm}$ and length of $375 \mathrm{~mm}$ ) inserted in a vertical ceramic electrical furnace. It was heated in continuous nitrogen flow of 9 $\mathrm{L} / \mathrm{h}$ at heating rate of $10^{\circ} \mathrm{C} / \mathrm{min}$ up to desired temperature maintained at fixed time. After heating, the reactor is cooled with the same flow nitrogen until room temperature. The samples obtained were washed with hot distilled water and sodium hydroxide $(0.1 \mathrm{~N})$ until constant $\mathrm{pH}$ of the solution was reached. Finally, samples were dried at $110^{\circ} \mathrm{C}$ for $24 \mathrm{~h}$ and finally kept in tightly closed bottles for later experiment use. The yield of the prepared activated carbons was estimated using the following Eq. 1:

$$
\text { Yield }(\%)=\frac{w_{c}}{w_{0}} \times 100
$$

Where:

$\mathrm{w}_{\mathrm{c}}=$ The weight of activated carbon

$\mathrm{w}_{0}=$ The weight of pomegranate peels

The main characteristics and adsorption properties of the optimal activated carbon prepared were compared with those of a Commercial Activated (CAC) known as adsorbent in aqueous solution. This material derives from the chemical activation of wood with phosphoric acid.

\section{Characterization methods}

Thermal analysis: The thermogravimetric analyses of pomegranate peels and phosphoric acid impregnated pomegranate peels were evaluated by Setaram TGA-DTA Model which was carried out in nitrogen atmosphere at rate of $10^{\circ} \mathrm{C} / \mathrm{min}$ and the temperature was between the ambient and $800^{\circ} \mathrm{C}$ for the raw $\mathrm{PP}$ and between the ambient and $500^{\circ} \mathrm{C}$ for impregnated $\mathrm{PP}$.

Textural characteristics: Textural characterization of the AC was carried out using $\mathrm{N}_{2}$ adsorption at $77 \mathrm{~K}$ using a Quantachrome Autosorb-1 apparatus. Before, the beginning of the experiments the sample was degassed at $300^{\circ} \mathrm{C}$ overnight under vacuum $<0.05$ mbar. The specific surface areas $\mathrm{S}_{\mathrm{BET}}$ was determined from isotherms using BET equation at relative pressure in the range 0.01-0.1. The total pore volume, $V_{\text {tot }}$ was estimated at a relative Pressure of $\mathrm{P} / \mathrm{P}^{0}$ near the unity. The micropore volume, 
$\mathrm{V}_{\text {mic }}$ was determined using Dubinin Radushkevich equation and the mesopore Volume, $\mathrm{V}_{\text {mes }}$ was calculated from the difference between $\mathrm{V}_{\text {tot }}$ and $\mathrm{V}_{\text {mic }}$. According to the relationship, $D_{P}=4 V_{t} / S_{B E T}$, the mean pore Diameter $\left(D_{p}\right)$ can be determined.

Chemical characterization: The surface chemistry characterization of the activated carbon was performed with Boehm titration, $\mathrm{pH}$ drift $\left(\mathrm{pH}_{\mathrm{pzc}}\right)$ and FTIR spectroscopy.

The Boehm titration method can be described as follows: $1 \mathrm{~g}$ of activated carbon were placed to a series of flask which contain $50 \mathrm{~mL}$ of $0.01 \mathrm{~N}$ sodium bicarbonate $\left(\mathrm{NaHCO}_{3}\right)$, sodium carbonate $\left(\mathrm{Na}_{2} \mathrm{CO}_{3}\right)$, sodium hydroxide $(\mathrm{NaOH})$, sodium ethoxide $\left(\mathrm{NaOC}_{2} \mathrm{H}_{5}\right)$ and hydrochloric acid. The flasks were sealed and shaken for $72 \mathrm{~h}$. After this time, the solutions were filtered and the $10 \mathrm{~mL}$ of each filtrate was pipetted and titrated with $0.1 \mathrm{~N}$ sodium hydroxide or hydrochloric acid, depending on the nature of solution used. The amount of acidic groups on the activated carbon is calculated under the assumption that $\mathrm{NaOC}_{2} \mathrm{H}_{5}$ neutralizes all acidic groups; $\mathrm{NaOH}$ neutralizes carboxylic, lactonic and phenolic groups; $\mathrm{Na}_{2} \mathrm{CO}_{3}$ neutralizes carboxylic and lactonic groups; $\mathrm{NaHCO}_{3}$ neutralizes only carboxylic group. The amount of basic groups was calculated from the amount of $\mathrm{HCl}$ which reacted with the carbon.

The $\mathrm{pH}_{\mathrm{PZC}}$ (point of zero charge) of activated carbon was measured by the $\mathrm{pH}$ drift method. The procedure of this method can be described as follows: $50 \mathrm{~mL}$ of 0.01 $\mathrm{mol} / \mathrm{L} \mathrm{NaCl}$ were prepared and added into a series of Erlenmeyer's. Then their $\mathrm{pH}$ were adjusted in range 2-12 using $0.1 \mathrm{~N} \mathrm{HCl}$ or $0.1 \mathrm{~N} \mathrm{NaOH}$ solutions. $0.15 \mathrm{~g}$ of activated carbon was the added to each solution. The final $\mathrm{pH}$ achieved after $48 \mathrm{~h}$ of agitation was measured and plotted as a function of initial $\mathrm{pH}$. The intersection of this curve with the first bisector gives the $\mathrm{pH}_{\mathrm{PZC}}$ of the activated carbons.

The FTIR spectrum of the PP and PPAC were recorded between 4000 and $400 \mathrm{~cm}^{-1}$ using Spectrum Two Perkin Elmer spectrometer equipped with DTGS detector with a resolution of $2 \mathrm{~cm}^{-1}$ and 32 scans.

Iodine number: The Iodine Number (NN) expressed in $\mathrm{mg} / \mathrm{g}$ gives an estimation of the surface area of adsorbant and is used to measure the porosity for pores larger than $1 \mathrm{~nm}$ in diameter (Wang et al., 2013).

Iodine number was measured by mixing $1 \mathrm{~g}$ of activated carbon with a particle size lower than $0.1 \mathrm{~mm}$ and dried with $10 \mathrm{~mL}$ of $5 \mathrm{wt} \% \mathrm{HCl}$ in a glass vessel. The latter is heated by a sand bath for $30 \mathrm{sec}$. After cooling the vessel to ambient temperature, $100 \mathrm{~mL}$ of iodine solution $(0.1 \mathrm{~mol} / \mathrm{l})$ is introduced. The suspension is shaken during $30 \mathrm{sec}$ and filtered using Whatman paper filter. The free iodine in the filtrate solution is titrated by a sodium thiosulfate solution $(0.1 \mathrm{~mol} / \mathrm{L})$.

Adsorption experiments: The adsorption capacities of the carbons were tested using Phenol (Ph), 2-Nitrophenol (2NP) and Methylene Blue (MB). The chemicals used were of analytical grade and were purchased from Prolabo.

Phenol (chemical formula $\mathrm{C}_{6} \mathrm{H}_{5} \mathrm{OH}, \mathrm{MW}$ : 94.11 $\mathrm{g} / \mathrm{mol}$ ) and 2-nitrophenol (chemical formula $\mathrm{C}_{6} \mathrm{H}_{4} \mathrm{NO}_{2} \mathrm{OH}$, MW: $139.11 \mathrm{~g} / \mathrm{mol}$ ) represent commonly encountered phenolic pollutants in water and wastewater treatment. A stock solution of phenol or 2-nitrophenol $(1 \mathrm{~g} / \mathrm{L})$ was prepared and suitably diluted to the required concentration.

Methylene blue is a basic dye (Chemical formula: $\mathrm{C}_{16} \mathrm{H}_{18} \mathrm{~N}_{3} \mathrm{SCl}$, type: cationic, molecule dimensions in $\mathrm{nm}$ $1.43 \times 0.61 \times 0.40$; MW: $319.85 \mathrm{~g} / \mathrm{moL}$ ). This dye was chosen because of its importance and wide applications in various fields such as analytical chemistry, aquaculture (antifungal) and biology (staining procedure) (Mahamad et al., 2015). In addition, the adsorption capacity of this molecule provides information on the presence of mesopores given that it is accessible to the pores which have diameters larger than $1.5 \mathrm{~nm}$ (Aygun et al., 2003).

A stock solution of methylene blue $(200 \mathrm{mg} / \mathrm{L})$ was prepared. Solutions at various concentrations are obtained by dilution.

The study of $\mathrm{Ph}, 2-\mathrm{NP}$ and $\mathrm{MB}$ adsorption was performed at temperature $30^{\circ} \mathrm{C}$ under continuous shaking. To obtain the equilibrium isotherms, a series of $250 \mathrm{~mL}$ Erlenmeyers flasks were employed. Each flask was filled with $200 \mathrm{~mL}$ of solute solution of varying concentrations (20-500 mg/L for Ph, 2-NP and 10-120 mg/L for MB). A known amount of activated carbon was added into each flask. The mixtures were then shaken for $4 \mathrm{~h}$, this time was considered adequate to reach equilibrium. At the end of this time, the content of each flask was filtered and the filtrate was analyzed by spectrophotometry absorption using a Shimatzu 1700 UV visible spectrophotometer at $270 \mathrm{~nm}(\mathrm{Ph}), 350 \mathrm{~nm}(2-\mathrm{NP})$ and $660 \mathrm{~nm}(\mathrm{MB})$. The amount of solute adsorbed at equilibrium $\left(\mathrm{q}_{\ominus} \mathrm{mg} / \mathrm{g}\right)$ was calculated by the following Eq. 2 :

$$
\mathrm{q}_{\mathrm{e}}=\frac{\mathrm{V}\left(\mathrm{C}_{0}-\mathrm{C}_{\mathrm{e}}\right)}{\mathrm{W}}
$$


Where:

$$
\begin{array}{ll}
\mathrm{C}_{0} \text { and } \mathrm{C}_{\mathrm{e}}= & \text { The initial and equilibrium concentration of } \\
& \text { the solute }(\mathrm{mg} / \mathrm{L}) \\
\mathrm{V} & =\text { Represents the solution volume }(\mathrm{L}) \\
\mathrm{W} & =\text { The mass of adsorbent }(\mathrm{g})
\end{array}
$$

Adsorption isotherms models: Adsorption isotherm models were applied to determine the relationship between adsorbate and adsorbent at equilibrium. In this study three commonly models Langmuir, Freundlich and Temkin were applied. The Langmuir model is expressed by Eq. 3:

$$
\mathrm{q}_{\mathrm{e}}=\frac{\mathrm{q}_{\mathrm{m}} \mathrm{K}_{\mathrm{L}} \mathrm{C}_{\mathrm{e}}}{1+\mathrm{K}_{\mathrm{L}} \mathrm{C}_{\mathrm{e}}}
$$

The Freundlich model is expressed by Eq. 4 :

$$
\mathrm{q}_{\mathrm{e}}=\mathrm{K}_{\mathrm{F}} \mathrm{C}_{\mathrm{e}}^{\frac{1}{\mathrm{n}}}
$$

The Temkin model is expressed by Eq. 5 :

$$
\mathrm{q}_{\mathrm{e}}=\mathrm{B}_{\mathrm{T}} \ln \left(\mathrm{A}_{\mathrm{T}} \mathrm{C}_{\mathrm{e}}\right)
$$

where, $C_{e}(m g / L)$ is the equilibrium concentration of solute in solution, $\mathrm{q}_{e}(\mathrm{mg} / \mathrm{g})$ is the amount of solute adsorbed at the equilibrium time, $\mathrm{q}_{\mathrm{m}}(\mathrm{mg} / \mathrm{g})$ is the maximum capacity, $\mathrm{K}_{\mathrm{L}}$ $(\mathrm{L} / \mathrm{mg})$ is the Langmuir constant, $\mathrm{K}_{\mathrm{F}}\left((\mathrm{mg} / \mathrm{g}) .(\mathrm{L} / \mathrm{mg})^{1 / 1 / n}\right)$ is the constant of adsorption capacity and $\mathrm{n}$ is the adsorption intensity, $\mathrm{A}_{\mathrm{T}}(\mathrm{L} / \mathrm{min})$ is the equilibrium binding constant and $\mathrm{B}_{\mathrm{T}}$ is the Temkin constant.

\section{RESULTS AND DISCUSSION}

Thermal analysis: Figure 1a shows TGA and Derivative Thermo Gravimetric (DTG) curves of raw permanganate peels. According to the figure, thermograms of untreated permanganate peels follow the usual shape for lignocellulosic materials, indicating three stages: the first one is below $150^{\circ} \mathrm{C}$ which is due to moisture loss. A weight loss of $5 \%$ is recorded. The main degradation is located in the temperature range from $150-400^{\circ} \mathrm{C}$. This stage consists of a major loss of weight (about $35 \%$ ). On DTG curves, two distinct peaks are clearly observed. The first, occurring at lower temperatures $\left(150-300^{\circ} \mathrm{C}\right)$ could be mainly corresponds to the hemicellulose decomposition, associated with a weight loss of $22 \%$. Meanwhile, the second peak $\left(300-400^{\circ} \mathrm{C}\right)$ was attributed to the degradation of cellulose with a mass loss of $13 \%$. After main decomposition, the weight loss decrease slowly indicating the third stage.
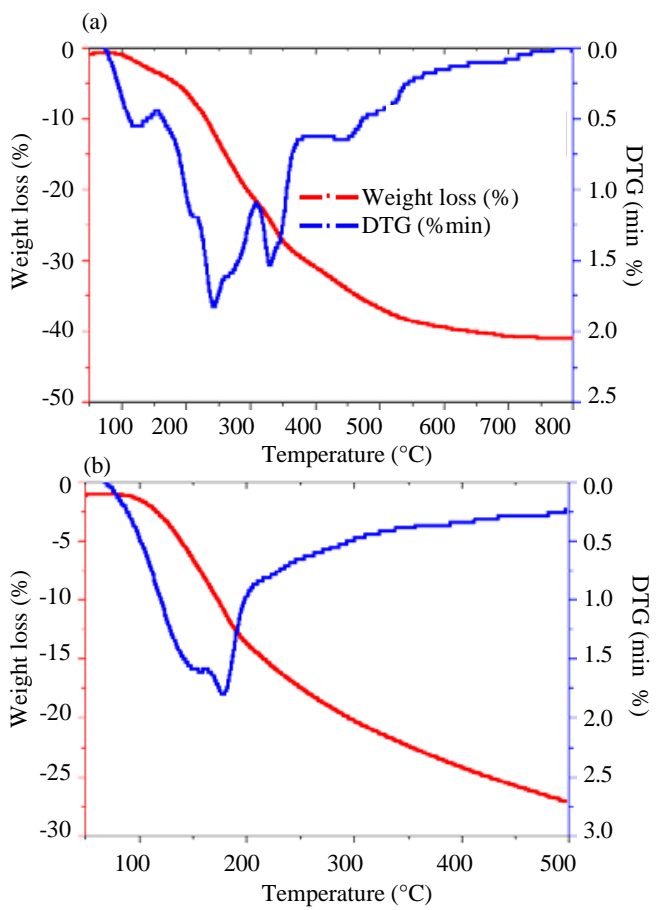

Fig. 1: TG-DTG of $\mathrm{PP}$; a) and $\mathrm{H}_{3} \mathrm{PO}_{4}$ impregnated $\mathrm{PP}$ and b) pyrolysis under $\mathrm{N}_{2}$ atmosphere at heating rate $10^{\circ} \mathrm{C} / \mathrm{min}$

In comparison to the untreated material, impregnation with phosphoric acid $\mathrm{H}_{3} \mathrm{PO}_{4}$ brings about remarkable modification to the pyrolysis of the precursor as shown in Fig. $1 \mathrm{~b}$. With the impregnation by $\mathrm{H}_{3} \mathrm{PO}_{4}$, the weight loss stages shifted to lower temperature whereby the main degradation of impregnated pomegranate peels is observed at a temperature range of $70-225^{\circ} \mathrm{C}$. These findings can be explained by the fact that $\mathrm{H}_{3} \mathrm{PO}_{4}$ acts as catalyst to promote the degradation of biopolymers, principally hemicellulose, cellulose and lignin (Zuo et al., 2012). In addition, the main degradation stage of impregnated permanganate peels involved only one step. This means that phosphoric acid removed impregnated materials from their origin shape of lignocellulosic biomass (Dobele et al., 1999).

In the other hand, the weight loss at $500^{\circ} \mathrm{C}$ of raw permanganate peels was $40 \%$, whilst only $27 \%$ of weight loss for impregnated permanganate peels. It is anticipated that $\mathrm{H}_{3} \mathrm{PO}_{4}$ reduced the weight loss of decomposition of cellulose (Nada and Hassan, 2003).

Effect of operating parameters on produced carbons: In order to produce optimal $\mathrm{AC}$ from $\mathrm{PP}$, the effects of the impregnation ratio of $\mathrm{H}_{3} \mathrm{PO}_{4}$ solution to $\mathrm{PP}$, impregnation time, activation temperature and time on the specific surface area and iodine number were investigated. 
Table 1: Effect of operating parameter on BET surface area and iodine number

\begin{tabular}{lcccccc}
\hline Impregnation ratio $(\mathrm{g} / \mathrm{g})$ & Impregnation time $(\mathrm{h})$ & Carbonisation temperature $\left({ }^{\circ} \mathrm{C}\right)$ & Carbonisation time $(\mathrm{h})$ & Sample & $\mathrm{S}_{\mathrm{BET}}\left(\mathrm{m}^{2} / \mathrm{g}\right)$ & $\mathrm{IN}(\mathrm{mg} / \mathrm{g})$ \\
\hline 2.0 & 3.0 & 400 & 3.0 & $\mathrm{AC} 2343$ & 779 & 653 \\
3.0 & 3.0 & 400 & 3.0 & $\mathrm{AC} 3343$ & 1318 & 773 \\
4.0 & 3.0 & 400 & 3.0 & $\mathrm{AC} 4343$ & 1465 & 775 \\
5.0 & 3.0 & 400 & 3.0 & $\mathrm{AC} 5343$ & 1287 & 762 \\
4.0 & 2.0 & 400 & 3.0 & $\mathrm{AC} 4243$ & 1597 & 813 \\
4.0 & 4.0 & 400 & 3.0 & $\mathrm{AC} 4443$ & 1082 & 734 \\
4.0 & 2.0 & 300 & 3.0 & $\mathrm{AC} 4233$ & 1168 & 575 \\
4.0 & 2.0 & 400 & 3.0 & $\mathrm{AC} 4253$ & 1346 & 724 \\
4.0 & 2.0 & 400 & 2.0 & $\mathrm{AC} 4242$ & 1000 & 519 \\
4.0 & 2.0 & 400 & $\mathrm{AC} 4244$ & 1429 & 805 \\
\hline
\end{tabular}

Table 2: Textural and yield of PPAC and CAC

\begin{tabular}{llllllll}
\hline $\mathrm{AC}$ & Activation agent & $\mathrm{S}_{\mathrm{BET}}\left(\mathrm{m}^{2} / \mathrm{g}\right)$ & $\mathrm{V}_{\mathrm{tot}}\left(\mathrm{cm}^{3} / \mathrm{g}\right)$ & $\mathrm{V}_{\text {mic }}\left(\mathrm{cm}^{3} / \mathrm{g}\right)$ & $\mathrm{V}_{\text {mes }}\left(\mathrm{cm}^{3} / \mathrm{g}\right)$ & $\mathrm{D}_{\mathrm{p}}(\mathrm{nm})$ & $\mathrm{Yield}(\%)$ \\
\hline $\mathrm{PPAA}$ & $\mathrm{H}_{3} \mathrm{PO}_{4}$ & 1597 & 1.118 & 1.002 & 0.116 & 2.99 & 33.4 \\
$\mathrm{CAC}$ & $\mathrm{H}_{3} \mathrm{PO}_{4}$ & 1377 & 1.23 & 0.905 & 0.325 & 3.84 & - \\
\hline
\end{tabular}

Effect of impregnation parameters on BET surface area and iodine number: The objective of this part is to prepare an optimal activated carbon based on the measurement of the BET specific surface area and iodine number. The two impregnations parameters ratio and time were varied.

Table 1 summarizes the effects of impregnation agent on the BET surface area and the iodine number of the activated carbon.

From Table 1 when the impregnation ratio goes from 2-3, the specific surface area increases considerably. It passes from $779-1465 \mathrm{~m}^{2} / \mathrm{g}$. In this step, there will be development of the microporous structure of activated carbon. In fact, new micropores are created due to the dehydrating effect of the chemical agent (Mahamad et al., 2015), hence, the increase in the specific surface area. Also, the volatile matter decreased while the fixed carbon content increased due to the pyrolytic effect where most of the organic substances are degraded and discharged as gas and liquids leaving a material with high carbon content (Mahamad et al., 2015). Arriving at a certain content of the impregnating agent, there will be formation of mesopores and macropores which are due to the enlargement of the micropores (Kong et al., 2013) which causes a decrease in the specific surface area.

The iodine number follows the same variation as the specific surface area but its value expressed in $\mathrm{mg} / \mathrm{g}$ is significantly lower than the specific surface area. This proves the presence of micropores with a diameter of $<1 \mathrm{~nm}$ which are accessible to the nitrogen molecule but not accessible to iodine. Based on these results, we set an impregnation ratio 4 .

The effect of the impregnation time in the range $2-4 \mathrm{~h}$ on surface area and iodine number of prepared activated carbon is shown in Table 2. An increase in the yield of activated carbon is observed which goes from $33.36 \%$ for duration of impregnation of $2 \mathrm{~h}$ to $36.22 \%$ for duration of impregnation of $4 \mathrm{~h}$. Hence, an increase of $2.86 \%$. The prolongation of the impregnation time facilitates the development of the mesoporosity shown by a reduction in the specific surface area from $1597 \mathrm{~m}^{2} / \mathrm{g}$ for an impregnation period of $2 \mathrm{~h}$ to $1082 \mathrm{~m}^{2} / \mathrm{g}$ for an impregnation period of $4 \mathrm{~h}$. As for the iodine number, it follows the same variation as the specific surface area. We note, here that a few work has been studied the effect of impregnation time on surface area and iodine number.

Looking at the results commented above an impregnation time of $2 \mathrm{~h}$ was selected as the most suitable for preparing activated carbon do to the high specific surface area and iodine number. After the study of the impregnation step, we choose as working conditions: impregnation ratio of 4 and impregnation time of $2 \mathrm{~h}$.

Effect of carbonization parameters on BET surface area and iodine number: The temperature and time of the carbonization step are key operating parameters of the operation.

The impregnated precursor is carbonized for $3 \mathrm{~h}$. However, the heat treatment temperature is varied between 300 and $500^{\circ} \mathrm{C}$ to obtain the activated carbon with the high specific surface area. The optimum temperature obtained is applied in the optimization of the carbonization time between 2 and $4 \mathrm{~h}$. The BET surface area increases with the increasing activation temperature from $300-400^{\circ} \mathrm{C}$ what can be attributed to the release of tars from the cross-linked framework generated by the chemical reagents treatment (Hsu and Teng, 2000). Increasing the temperature beyond $400^{\circ} \mathrm{C}$, allows a drop in the specific surface area that can be attributed to the shrinkage in the carbon structure, leading to a reduction in porosity ( $\mathrm{Hsu}$ and Teng, 2000). The same result has also been reported by Prahas et al. (2008). In general, the effect of the carbonization temperature on the microporosity and therefore, on the BET specific surface area, depends on the impregnation ratio (Girgis and Hendawy, 2002; Philip and Girgis, 1996). 
Table 3: Textural characteristics of PPAC and some others ACs prepared from agricultural waste

\begin{tabular}{|c|c|c|c|c|c|c|c|}
\hline Precursor & Activation agent & $\mathrm{S}_{\mathrm{BET}}\left(\mathrm{m}^{2} / \mathrm{g}\right)$ & $\mathrm{V}_{\text {tot }}\left(\mathrm{cm}^{3 / \mathrm{g}}\right)$ & $\mathrm{V}_{\text {mic }}\left(\mathrm{cm}^{3} / \mathrm{g}\right)$ & $\mathrm{V}_{\operatorname{mes}}\left(\mathrm{cm}^{3} / \mathrm{g}\right)$ & $\mathrm{D}_{\mathrm{p}}(\mathrm{nm})$ & References \\
\hline Pomegranate peels & $\mathrm{H}_{3} \mathrm{PO}_{4}$ & 1597 & 1.118 & 1.002 & 0.116 & 2.99 & This study \\
\hline Pomegranate peels & $\mathrm{KOH}$ & 1405 & 0.617 & 0.6017 & 0.0153 & 1.757 & Saadi et al. (2016) \\
\hline Pomegranate peels & $\mathrm{H}_{3} \mathrm{PO}_{4}$ & 686 & 0.5053 & - & - & 1.363 & Senthikumar et al. (2017) \\
\hline Coconut Shell & $\mathrm{H}_{3} \mathrm{PO}_{4}$ & 891 & 0.7233 & 0.2680 & 0.4546 & - & Wang et al. (2013) \\
\hline Jatrophacurcas fruit Shell & $\mathrm{NaOH}$ & 1873 & 1.312 & - & - & 2.80 & Tongpoothometal. (2011) \\
\hline Olive stones & $\mathrm{H}_{3} \mathrm{PO}_{4}$ & 1218 & 0.6 & 0.5 & 0.1 & 1.1 & Yakout and Sharaf \\
\hline Sky fruit husk & $\mathrm{H}_{3} \mathrm{PO}_{4}$ & 1211.57 & 0.84 & 0.15 & - & 2.778 & Njoku et al. (2014) \\
\hline Soybean straw & $\mathrm{ZnCl}_{2}$ & 2271 & 1.479 & 0.793 & 0.686 & 2.60 & Miao et al. (2013) \\
\hline Jackfruit peel & $\mathrm{H}_{3} \mathrm{PO}_{4}$ & 1260 & 0.733 & 0.471 & 0.262 & - & Prahas et al. (2008) \\
\hline
\end{tabular}

Therefore, carbonization temperature of $400^{\circ} \mathrm{C}$ was considered as the optimum for further optimization process. In most of the research work interested on the production of activated carbon from biomass using phosphoric acid as activation agent, the carbonization temperature which results in a developed porosity is in the range $350-450^{\circ} \mathrm{C}$ (Reddy et al., 2012; Gonzalez-Serrano et al., 2004). The effect of optimum activation time was determined for 2-4 $\mathrm{h}$. The highest specific surface area and iodine number were $1597 \mathrm{~m}^{2} / \mathrm{g}$ and $812 \mathrm{mg} / \mathrm{g}$, respectively. The sample having these characteristics was obtained at activation time $3 \mathrm{~h}$.

As seen from the Table 1 while the activation time increased from 2-3 h, the $\mathrm{S}_{\mathrm{BET}}$ and $\mathrm{IN}$ increased from 1000 to $1597 \mathrm{~m}^{2} / \mathrm{g}$ and from $519-812 \mathrm{mg} / \mathrm{g}$, respectively. However, the increase of activation time from 3-4 h, adversely affected the surface area and iodine number. Probably a high carbonization time causes the collapse of some pores resulting to lower pores volume and surface area (Saygili et al., 2015; Wang et al., 2011).

In summary, the activated carbon with the highest specific surface area and iodine number is named AC4243 in Table 1. Its specific surface area is $1597 \mathrm{~m}^{2} / \mathrm{g}$ and its iodine number is $813 \mathrm{mg} / \mathrm{g}$. The optimum conditions which are determined previously and resulting in this activated carbon are an impregnation ratio 4 , an impregnation time $2 \mathrm{~h}$, a carbonization temperature $400^{\circ} \mathrm{C}$ and a carbonization time $3 \mathrm{~h}$. In the rest of the text, the optimal $\mathrm{AC}$ is called PPAC.

\section{Characterization of the optimal activated carbon}

Textural characteristics: Figure 2 illustrates the adsorption-desorption isotherm of nitrogen at $77 \mathrm{~K}$ onto PPAC. The isotherm is a mixture of type $i$ at low pressure and type 4 at intermediate and high pressure based on IUPAC classification. Adsorption isotherm presents a sharp increase in the adsorbed volume up to a $\mathrm{P} / \mathrm{P}_{0}$ of 0.1 which was attributed to the presence of micropores. However, a progressive increase in this volume in the entire range of relative pressure could be attributed to the presence of mesopores. In addition the presence of the small hysteresis loop in the adsorption-desorption isotherms confirms the existence of this mesoporosity.

The adsorption isotherm of this $\mathrm{AC}$ showed a good agreement with those reports in the literatures (Tongpoothorn et al., 2011; Reddy et al., 2012).

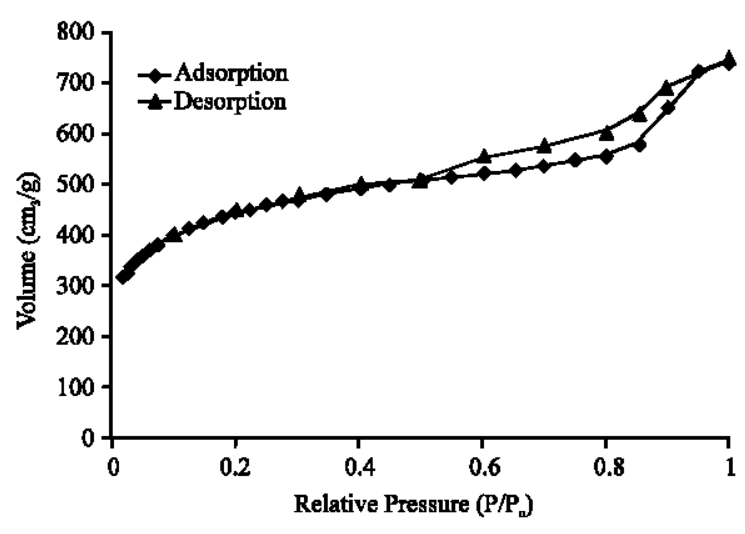

Fig. 2: Nitrogen adsorption-desorption isotherms of PPAC

The textural characteristics (BET surface area, pores volumes and average pore diameter) of PPAC obtained from adsorption-desorption isotherms were presented in Table 3. As shown from this table, PPAC has a $S_{\mathrm{BET}}$ near $1600 \mathrm{~m}^{2} / \mathrm{g}$ which is over the acceptable range for commercial activated carbons (500-1500 $\left.\mathrm{m}^{2} / \mathrm{g}\right)$ (Tongpoothorn et al., 2011).

Regarding the porosity of this $\mathrm{AC}$, it contains both microporous and mesoporous; nevertheless, the micropore volume $\left(1.002 \mathrm{~cm}^{3} / \mathrm{g}\right)$ is larger than mesopore volume $\left(0.116 \mathrm{~cm}^{3} / \mathrm{g}\right)$. Indeed, the fraction of the microporosity (ratio of the micropore volume to the total pore volume) is about $90 \%$. However, the mesoporosity represents $10 \%$. The average pore diameter of $2.99 \mathrm{~nm}$ confirms the presence of this mesoporosity.

Textural characteristics were comparable to those of other activated carbons prepared from agricultural waste by chemical process and even better in some cases.

Chemical characteristics of PPAC: The previous mentioned textural characteristics are not the only responsible for the effectiveness of the $\mathrm{AC}$ as adsorbent or catalyst but there are also the chemical characteristic $\left(\mathrm{pH}_{\mathrm{pzc}}\right.$ and oxygenated groups at the surface $)$.

The $\mathrm{pH}_{\mathrm{pzc}}$ and Boehm acid-base titration results for pomegranate peels and PPAC are shown in Table 4. As can be seen, $\mathrm{PP}$ has a $\mathrm{pH}_{\mathrm{pzc}}$ of 5.03 which shows its acidic nature. This being justified by the number of surface acid groups which is $3.9 \mathrm{meq} / \mathrm{g}$. This acidity comes essentially from the presence of phenolic groups which is $3.1 \mathrm{meq} / \mathrm{g}$. 
Table 4: pHpzc and surface functional groups of PP, PPAC and CAC Acidic surface functional groups (meq/g)

\begin{tabular}{llcccccc} 
Materials & pHpzc & Carboxyl & Lactone & Phenol & Carbonyl & Acidic groups & Basic surface functional groups (meq/g) \\
\hline PP & 5.03 & 0.8 & 0.00 & 3.10 & 0.0 & 3.9 & 0.00 \\
PPAC & 2.80 & 0.5 & 0.30 & 0.40 & 0.2 & 1.4 & 0.15 \\
CAC & 5.00 & 0.1 & 0.35 & 0.45 & 1.1 & 2.0 & 0.05 \\
\hline
\end{tabular}
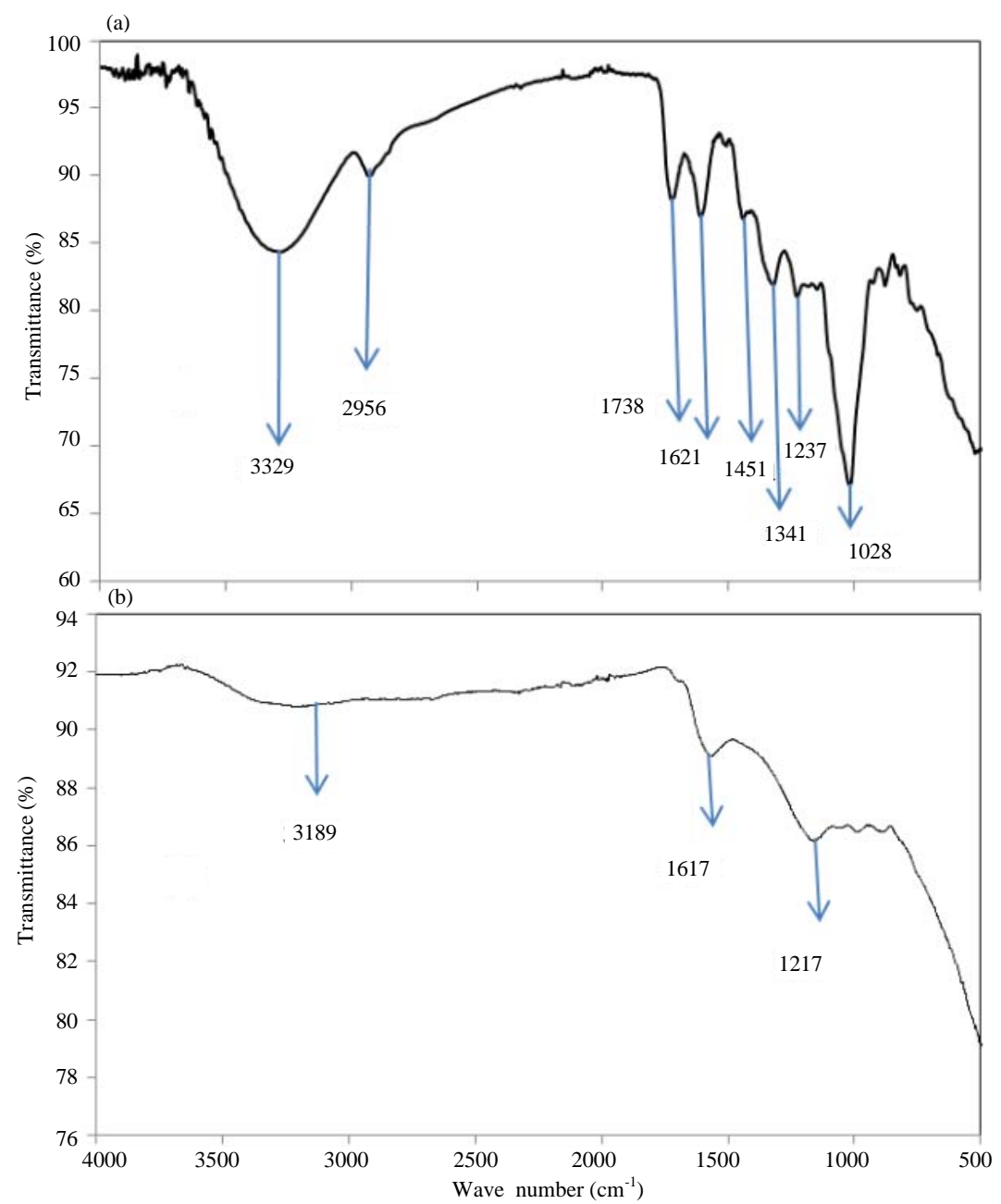

Fig. 3: a) FTIR Spectra for PP and b) PPAC

We note the presence of a small amount of carboxyl groups $(0.8 \mathrm{meq} / \mathrm{g})$ and the absence of lactone groups. As for the basic groups of surface, they are nonexistent. The impregnation of this raw material with phosphoric acid and its carbonization at $500^{\circ} \mathrm{C}$ reduces the number of acidic groups on the surface from 3.9-1.4 meq $/ \mathrm{g}$. Indeed, during the carbonization, there will be decomposition of certain functions in the form of $\mathrm{CO}$ and $\mathrm{CO}_{2}$. This is due to the instability of acid groups at high temperature (Prahas et al., 2008). Compared to the lower carbonyl group number $(0.2 \mathrm{meq} / \mathrm{g}$ for PPAC vs. CAC, it can be seen that the PPAC has a significantly 1.1 meq/g for $\mathrm{CAC}$ ). The phenol and lactone contents are close to those of the prepared AC. A few number of basic groups appears in the PPAC $(0.15 \mathrm{meq} / \mathrm{g})$ due to thermal treatment of the raw material (Cazetta et al., 2011). This number is even lower in the case of the CAC $(0.05$ $\mathrm{meq} / \mathrm{g}$ ). The spectra of the pomegranate peels and its activated carbon are shown in Fig. 3. As seen in the Fig. 3 , the spectra of the raw material show a strong wide 

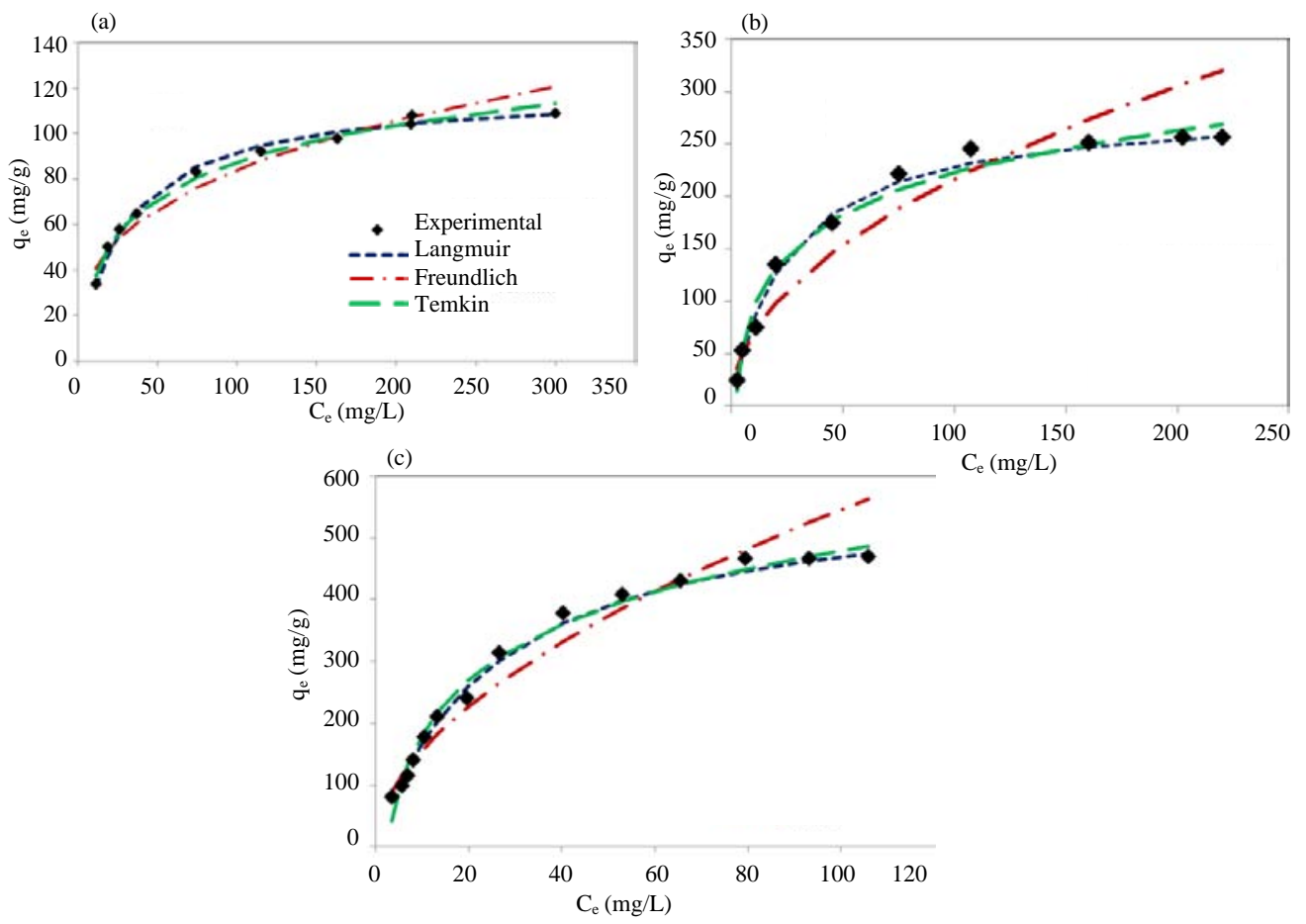

Fig. 4: a) Adsorption isotherms of $\mathrm{Ph}$; b) 2-NP and $\mathrm{MB}$ and c) onto PPAC at $30^{\circ} \mathrm{C}$

\begin{tabular}{|c|c|c|c|c|c|c|c|c|c|}
\hline \multirow[b]{2}{*}{ Adsorbate } & \multicolumn{3}{|c|}{ Langmuir } & \multicolumn{3}{|c|}{ Freundlich } & \multicolumn{3}{|l|}{ Temkin } \\
\hline & $K_{\mathrm{I}}(1 / g)$ & $\mathrm{q}_{8}(\mathrm{mg} / \mathrm{g})$ & $\mathrm{R}^{2}$ & $\mathrm{~K}_{\mathrm{F}}$ & $\mathrm{n}$ & $\mathrm{R}^{2}$ & $A_{T}$ & $\mathrm{~B}_{\mathrm{T}}$ & $\mathrm{R}^{2}$ \\
\hline$\overline{\mathrm{Ph}}$ & 0.0341 & 119 & 0.9984 & 18.427 & 3.033 & 0.9516 & 0.4584 & 22.951 & 0.9922 \\
\hline 2-NP & 0.0398 & 286 & 0.9979 & 22.540 & 2.033 & 0.9359 & 0.519 & 56.562 & 0.9808 \\
\hline MB & 0.0395 & 588 & 0.995 & 44.785 & 1.805 & 0.9648 & 0.397 & 130.44 & 0.9868 \\
\hline
\end{tabular}

absorption band with a maximum at around $3329 \mathrm{~cm}^{-1}$. It is attributed to hydroxyl groups (Gurten et al., 2012; Cazetta et al., 2011). The bands located at around $2956 \mathrm{~cm}^{-1}$ indicated the presence of $\mathrm{C}-\mathrm{H}$ band stretching in carboxylic acids (Gao et al., 2016). The relatively band at $1733 \mathrm{~cm}^{-1}$ and $1621 \mathrm{~cm}^{-1}$ was ascribed to $\mathrm{C}=\mathrm{O}$ stretching from aldehydes, ketones or carboxyls groups (Deng et al., 2010). The band at $1451 \mathrm{~cm}^{-1}$ was attributed to symmetrical angular deformation on the plane of methylene groups (Vargas et al., 2011). Finally, the region between $1350 \mathrm{~cm}^{-1}$ and $900 \mathrm{~cm}^{-1}$ is ascribed to $\mathrm{C}-\mathrm{O}$ and $\mathrm{C}=\mathrm{O}$ vibrations (Al-Bahri et al., 2012). PP spectra is similar to others lignocellulosic materials such as flamboyant pods (Vargas et al., 2011), cotton stalk (Deng et al., 2010) and grape waste (Saygili et al., 2015).

Figure $3 \mathrm{~b}$ shows the FTIR spectra of PPAC. Compared to PP spectra (Fig. 3a), we can show the disappearance of the most absorption bands. This is due to the decomposition of functional groups as volatile matter in the carbonization and activation process at high temperature (Saygili et al., 2015). This result confirms Boehm's analysis of the raw material and activated carbon. The bands at $3211 \mathrm{~cm}^{-1}$ correspond to $\mathrm{OH}$ stretching in hydroxyl functional groups involved in hydrogen banding possibly due to the water adsorbed (Reddy et al., 2012). Two others small picks can be observed. The first peak appeared at $1617 \mathrm{~cm}^{-1}$ can be attributed to the $\mathrm{C}=\mathrm{O}$ axial deformation of aldehyde, ketone, lactone and carboxyl groups and the second peak observed at $1217 \mathrm{~cm}^{-1}$ might be ascribed to the presence of C-O aliphatic esters (Mahamad et al., 2015).

Adsorption isotherms: Adsorption isotherms of $\mathrm{Ph}, 2 \mathrm{NP}$ and $\mathrm{MB}$ by PPAC are shown in Fig. 4. The experimental equilibrium data of three solutes are fitted by Langmuir (Eq. 3), Freundlich (Eq. 4) and Temkin (Eq. 5).

The fitted parameters of the Langmuir, Freundlich and Temkin equations are summarized in Table 5. Based on the correlation coefficient $\left(\mathrm{R}^{2}\right)$ obtained the Langmuir model with $\mathrm{R}^{2}$ more than 0.995 is more suitable to describe the adsorption process of $\mathrm{Ph}, 2 \mathrm{NP}$ and $\mathrm{MB}$ onto PPAC than the other two models. This implied the homogeneous and the monolayer coverage of these molecules on the surface of AC (Deng et al., 2010). The 
Table 6: Reported Ph, 2-NP and MB capacities of AC in literature

\begin{tabular}{|c|c|c|c|c|}
\hline$\underline{1 .}$ & Precursor & $q_{m, p H}(m g / g)$ & $q_{m}=2-\mathrm{NP}(\mathrm{mg} / \mathrm{g})$ & $\mathrm{q}_{\mathrm{m}-\mathrm{MB}}(\mathrm{mg} / \mathrm{g})$ References \\
\hline Pomegranate peels & 119 & & & El-Naas et al. $(2010)$ \\
\hline Date-pits & 262.3 & & & Hameed and Rahman (2008) \\
\hline Rattan sawdust & 149.25 & & & \\
\hline \multicolumn{5}{|l|}{ Bituminous coal: } \\
\hline Black Water & 76.9 & & & Teng and Hsieh (1999) \\
\hline Mt Thorley & 138 & & & Teng and Hsieh (1999) \\
\hline Olive stones & 200 & & & Bedoui et al. (2014) \\
\hline Pomegranate peels & & 286 & & Altaher and Dietrich (2014) \\
\hline Date pits & & 142.9 & & Gokturk and Kaluc (2008) \\
\hline Commercial AC & & 256.41 & & Bedoui et al. (2014) \\
\hline Olive stones & & 500 & & \\
\hline Pomegranate peels & & & 588 & This study \\
\hline Pomegranate peels & & & 556 & Saadi et al. (2016) \\
\hline Commercial AC & & & 333 & Saadi et al. (2016) \\
\hline Grape waste & & & 417 & Saygili et al. (2015) \\
\hline Fir wood & & & 579.97 & Wu and Tseng (2006) \\
\hline Corncob & & & 28.65 & El-Sayed et al. (2014) \\
\hline Corncobs & & & 208 & El-Hendawy (2005) \\
\hline Date palm pits & & & 455 & Reddy et al. (2012) \\
\hline Pineapple waste biomass & & & 288.34 & Mahamed et al. (2015) \\
\hline Olive stones & & & 303 & Najar-Souissi et al. (2005) \\
\hline
\end{tabular}

maximum adsorption capacity $\left(\mathrm{q}_{\mathrm{m}}\right)$ of $\mathrm{Ph}, 2-\mathrm{NP}$ and $\mathrm{MB}$ on the $\mathrm{PPAC}$ at $30^{\circ} \mathrm{C}$ were 119,286 and $588 \mathrm{mg} / \mathrm{g}$, respectively.

A comparison of the adsorption capacities for these molecules by other ACs is displayed in Table 6. As it can be shown, the pomegranate peels is a promising precursor for preparing $\mathrm{AC}$ mainly in the removal of organic dyes in solution.

\section{CONCLUSION}

The transformation of the pomegranate peels into activated carbons by a phosphoric acid chemical process was carried out for different operating parameters in order to determine the optimal conditions. The PPAC with the highest specific surface area is obtained for these conditions: $4: 1(\mathrm{w} / \mathrm{w}) \mathrm{H}_{3} \mathrm{PO}_{4}(50 \%)$ to $\mathrm{PP}$ ratio, $2 \mathrm{~h}$ time of impregnation, $400^{\circ} \mathrm{C}$ carbonization temperature and $3 \mathrm{~h}$ carbonization time.

The optimal AC has $\mathrm{S}_{\mathrm{BET}}$ of about $1600 \mathrm{~m}^{2} / \mathrm{g}, \mathrm{V}_{\text {tot }} 1.118$ $\mathrm{cm}^{3} / \mathrm{g}, \mathrm{V}_{\text {mic }} 90 \%, \mathrm{~V}_{\text {mes }} 10 \%, \mathrm{D}_{\mathrm{p}} 30 \AA$ and $\mathrm{pH}{ }_{\mathrm{pzc}} 2.8$. It contains acid functions at its surface of about $1.4 \mathrm{meq} / \mathrm{g}$ while the number of basic groups is very small (0.15 meq $/ \mathrm{g})$.

The PPAC is applied for the adsorption of two phenolic compounds: phenol and 2-nitrophenol and an organic dye methylene blue in the aqueous phase. The adsorption isotherms follow the Langmuir model for the three molecules. The adsorption capacities, $\mathrm{q}_{\mathrm{m}}$ of phenol, 2-nitrophenol and methylene blue are 119, 286 and $588 \mathrm{mg} / \mathrm{g}$, respectively. In conclusion, pomegranate peals can be good precursors for the preparation of activated carbon which can find its application in the field of waters and wastewater treatment particular for the treatment of cationic organic dyes.

\section{ACKNOWLEDGEMENT}

This research was supported by the Ministry of the Higher Education and Scientific Research in Tunisia.

\section{REFERENCES}

Ahmed, M.J., 2011. Preparation of activated carbons from date stones by chemical activation method using $\mathrm{FeCl}_{3}$ and $\mathrm{ZnCl}_{2}$ as activating agents. J. Eng., 17: 1007-1022.

Al Bahri, M., L. Calvo, M.A. Gilarranz and J.J. Rodriguez, 2012. Activated carbon from grape seeds upon chemical activation with phosphoric acid: Application to the adsorption of diuron from water. Chem. Eng. J., 203: 348-356.

Altaher, H. and A.M. Dietrich, 2014. Characterizing o-and p-nitrophenols adsorption onto innovative activated carbon prepared from date pits. Water Sci. Technol., 69: $31-37$.

Aygun, A., S. Yenisoy-Karakas and I. Duman, 2003. Production of granular activated carbon from fruit stones and nutshells and evaluation of their physical, chemical and adsorption properties. Microporous Mesoporous Mater., 66: 189-195.

Bedoui, A., S. Souissi-Najar and A. Ouederni, 2014. Characterization and phenols adsorption of olive stones based activated carbon. J. Intl. Environ. Appl. Sci., 9: 182-193.

Budinova, T., E. Ekinci, F. Yardim, A. Grimm and E. Bjornbom et al., 2006. Characterization and application of activated carbon produced by $\mathrm{H}>\mathrm{sub}>3 \mathrm{PO}_{4}$ and water vapor activation. Fuel Proc. Technol., 87: 899-905. 
Caturla, F., M. Molina-Sabio and F. Fordriguez-Reinon, 1991. Preparation of activated carbon by chemical activation with $\mathrm{ZnCl}$. Carbon, 29: 999-1007.

Cazetta, A.L., A.M. Vargas, E.M. Nogami, M.H. Kunita and M.R. Guilherme et al., 2011. NaOH-activated carbon of high surface area produced from coconut shell: Kinetics and equilibrium studies from the methylene blue adsorption. Chem. Eng. J., 174: 117125.

Cheenmatchaya, A. and S. Kungwankunakorn, 2014. Preparation of activated carbon derived from rice husk by simple carbonization and chemical activation for using as gasoline adsorbent. Intl. J. Environ. Sci. Dev., 5: 171-175.

Deng, H., G. Li, H. Yang, J. Tang and J. Tang, 2010. Preparation of activated carbons from cotton stalk by microwave assisted $\mathrm{KOH}$ and $\mathrm{K}_{2} \mathrm{CO}_{3}$ activation. Chem. Eng. J., 163: 373-381.

Dobele, G., G. Rossinskaja, G. Telysheva, D. Meier and O. Faix, 1999. Cellulose dehydration and depolymerization reactions during pyrolysis in the presence of phosphoric acid. J. Anal. Appl. Pyrol., 49: $307-317$.

El-Hendawy, A.N.A., 2005. Surface and adsorptive properties of carbons prepared from biomass. Appl. Surf. Sci., 252: 287-295.

El-Naas, M.H., S. Al-Zuhair and M. Abu-AlHaija, 2010. Removal of phenol from petroleum refinery wastewater through adsorption on date-pit activated carbon. Chem. Engin. J., 162: 997-1005.

El-Sayed, G.O., M.M. Yehia and A.A. Asaad, 2014. Assessment of activated carbon prepared from corncob by chemical activation with phosphoric acid. Water Resour. Ind., 7: 66-75.

Gao, Y., Q. Yue and B. Gao, 2016. Insights into properties of activated carbons prepared from different raw precursors by pyrophosphoric acid activation. J. Environ. Sci., 41: 235-243.

Girgis, B.S. and A.N.A. El-Hendawy, 2002. Porosity development in activated carbons obtained from date pits under chemical activation with phosphoric acid. Microporous Mesoporous Mater., 52: 105-117.

Girgis, B.S. and M.F. Ishak, 1999. Activated carbon from cotton stalks by impregnation with phosphoric acid. Mater. Lett., 39: 107-114.

Gokturk, S. and S. Kaluc, 2008. Removal of selected organic compounds in aqueous solutions by activated carbon. J. Environ. Sci. Technol., 1: 111-123.

Gonzalez-Serrano, E., T. Cordero, J. Rodriguez-Mirasol, L. Cotoruelo and J.J. Rodriguez, 2004. Removal of water pollutants with activated carbons prepared from $\mathrm{H}_{3} \mathrm{PO}_{4}$ activation of lignin from kraft black liquors. Water Res., 38: 3043-3050.
Gurten, I.I., M. Ozmak, E. Yagmur and Z. Aktas, 2012. Preparation and characterisation of activated carbon from waste tea using $\mathrm{K}_{2} \mathrm{CO}_{3}$. Biomass Bioenergy, 37 : 73-81.

Hameed, B.H. and A.A. Rahman, 2008. Removal of phenol from aqueous solutions by adsorption onto activated carbon prepared from biomass material. J. Hazard. Mater., 160: 576-581.

Hayash, J., T. Horikawa, I. Takeda, K. Muroyama and F.N. Ani, 2002. Preparing activated carbon from various nutshells by chemical activation with $\mathrm{K}_{2} \mathrm{CO}_{3}$. Carbon, 40: 2181-2186.

Hsu, L.Y. and H. Teng, 2000. Influence of different chemical reagents on the preparation of activated carbons from bituminous coal. Fuel Proc. Technol., 64: 155-166.

Kalderis, D., S. Bethanis, P. Paraskeva and E. Diamadopoulos, 2008. Production of activated carbon from bagasse and rice husk by a single-stage chemical activation method at low retention times. Bioresour. Technol., 99: 6809-6816.

Kong, J., Q. Yue, L. Huang, Y. Gao and Y. Sun et al., 2013. Preparation, characterization and evaluation of adsorptive properties of leather waste based activated carbon via physical and chemical activation. Chem. Eng. J., 221: 62-71.

Lam, E. and J.H. Luong, 2014. Carbon materials as catalyst supports and catalysts in the transformation of biomass to fuels and chemicals. ACS. Catal., 4: 33933410 .

Lim, W.C., C. Srinivasakannan and N. Balasubramanian, 2010. Activation of palm shells by phosphoric acid impregnation for high yielding activated carbon. J. Anal. Applied Pyrolysis, 88: 181-186.

Mahamad, M.N., M.A.A. Zaini and Z.A. Zakaria, 2015. Preparation and characterization of activated carbon from pineapple waste biomass for dye removal. Intl. Biodeterior. Biodegrad., 102: 274-280.

Marsh, H. and F.R. Reinoso, 2006. Activated Carbon. Elsevier, New York, USA., ISBN:9780080455969, Pages:554.

Miao, Q., Y. Tang, J. Xu, X. Liu, L. Xiao and Q. Chen, 2013. Activated carbon prepared from soybean straw for phenol adsorption. J. Taiwan Inst Chem. E., 44: 458-465.

Moreno-Castilla, C., 2004. Adsorption of organic molecules from aqueous solutions on carbon materials. Carbon, 42: 83-94.

Nabais, J.M.V., C. Laginhas, M.M.L.R. Carrott, P.J.M. Carrott, J.E.C. Amoros and A.V.N. Gisbert, 2013. Surface and porous characterisation of activated carbons made from a novel biomass precursor, the esparto grass. Applied Surf. Sci., 265: 919-924. 
Nabais, J.M.V., C.E.C. Laginhas, P.J.M. Carrott and M.R. Carrott, 2011. Production of activated carbons from almond shell. Fuel Proc. Technol., 92: 234-240.

Nada, A.A.M. and M.L. Hassan, 2003. Phosphorylated cation-exchangers from cotton stalks and their constituents. J. Appl. Polym. Sci., 89: 2950-2956.

Najar-Souissi, S., A. Ouederni and A. Ratel, 2005. Adsorption of dyes onto activated carbon prepared from olive stones. J. Environ. Sci., 17: 998-1003.

Njoku, V.O., M.A. Islam, M. Asif and B.H. Hameed, 2014. Utilization of sky fruit husk agricultural waste to produce high quality activated carbon for the herbicide Bentazon adsorption. Chem. Eng. J., 251: 183-191.

Ouederni, A., S. Souissi-Najar and A. Ratel, 2006. Activated carbon from olive stones by a two step process: Influence of production parameters on textural characteristics. Ann. Chim. Sci. Mat., 31: 151 167.

Philip, C.A. and B.S. Girgis, 1996. Adsorption characteristics of microporous carbons from apricot stones activated by phosphoric acid. J. Chem. Technol. Biotechnol. Intl. Res. Proc. Environ. Clean, 67: 248-254.

Prahas, D., Y. Kartika, N. Indraswati and S. Ismadji, 2008. Activated carbon from jackfruit peel waste by $\mathrm{H}_{3} \mathrm{PO}_{4}$ chemical activation: Pore structure and surface chemistry characterization. Chem. Eng. J., 140: 32-42.

Reddy, K.S.K., A. Al Shoaibi and C. Srinivasakannan, 2012. A comparison of microstructure and adsorption characteristics of activated carbons by $\mathrm{CO}_{2}$ and $\mathrm{H}_{3} \mathrm{PO}_{4}$ activation from date palm pits. New Carb. Mater., 27: 344-351.

Saad, H., F.C.E. Bouhtoury, A. Pizzi, K. Rode and B. Charrier et al., 2012. Characterization of pomegranate peels tannin extractives. Ind. Crop. Prod., 40: 239-246.

Saadi, W., S.N. Souissi and A. Ouederni, 2016. Pomegranate Peels precursor used in the synthesis of activated Carbon: Application in the wastewater treatment. J. Intl. Environ. Appl. Sci., 11: 318-330.

Saygili, H., F. Guzel and Y. Onal, 2015. Conversion of grape industrial processing waste to activated carbon sorbent and its performance in cationic and anionic dyes adsorption. J. Cleaner Prod., 93: 84-93.
Senthilkumar, T., S.K. Chattopadhyay and L.R. Miranda, 2017. Optimization of activated carbon preparation from pomegranate peel (Punica granatum peel) using RSM. Chem. Eng. Commun., 204: $238-248$

Serafin, J., U. Narkiewicz, A.W. Morawski, R.J. Wrobel and B. Michalkiewicz, 2017. Highly microporous activated carbons from biomass for $\mathrm{CO} 2$ capture and effective micropores at different conditions. J. $\mathrm{CO}_{2}$ Util., 18: 73-79.

Teng, H. and C.T. Hsieh, 1999. Liquid-phase adsorption of phenol by activated carbons prepared from bituminous coals with different oxygen contents. J. Chem. Technol. Biotechnol. Intl. Res. Proc. Environ. Clean, 74: 123-130.

Tongpoothorn, W., M. Sriuttha, P. Homchan, S. Chanthai and C. Ruangviriyachai, 2011. Preparation of activated carbon derived from Jatropha curcas fruit shell by simple thermo-chemical activation and characterization of their Physico-chemical properties. Chem. Eng. Res. Des., 89: 335-340.

Vargas, A.M., A.L. Cazetta, C.A. Garcia, J.C. Moraes and E.M. Nogami et al., 2011. Preparation and characterization of activated carbon from a new raw lignocellulosic material: Flamboyant (Delonix regia) pods. J. Environ. Manage., 92: 178-184.

Wang, L., Y. Guo, B. Zou, C. Rong and X. Ma et al., 2011. High surface area porous carbons prepared from hydrochars by phosphoric acid activation. Bioresour. Technol., 102: 1947-1950.

Wang, X., D. Li, W. Li, J. Peng and H. Xia et al., 2013. Optimization of mesoporous activated carbon from coconut shells by chemical activation with phosphoric acid. BioResources, 8: 6184-6195.

Wu, F.C. and R.L. Tseng, 2006. Preparation of highly porous carbon from fir wood by $\mathrm{KOH}$ etching and $\mathrm{CO}_{2}$ gasification for adsorption of dyes and phenols from water. J. Colloid Interf. Sci., 294: 21-30.

Zuo, S., Z. Xiao and J. Yang, 2012. Evolution of gaseous products from biomass pyrolysis in the presence of phosphoric acid. J. Anal. Appl. Pyrol., 95: 236-240. 